Rev Biomed 2003; 14:215-216.

\title{
Las muertes maternas en Yucatán: un llamado a la investigación-acción.
}

\author{
Carta al Editor
}

Elsa Rodríguez-Angulo ${ }^{1}$, Francisco Uicab-Alonzo ${ }^{2}$, Judith Ortega-Canto ${ }^{1}$.

${ }^{1}$ Centro de Investigaciones Regionales “Dr. Hideyo Noguchi”, Universidad Autónoma de Yucatán, ${ }^{2}$ Secretaría de Salud de Yucatán, Mérida, Yucatán, México.

El proceso reproductivo es concebido como un evento "natural" que no amerita cuidados especiales (1). Sin embargo, es durante el embarazo, parto y puerperio, cuando la mujer es vulnerable a sufrir daños a la salud originados por factores internos o externos, que rompen la homeostasis de su organismo y pueden desencadenarle la muerte. En la literatura mundial, la mortalidad materna sigue siendo un problema de salud, sobretodo en los países en vías de desarrollo. Una defunción materna es la muerte de una mujer mientras está embarazada o dentro de los 42 días siguientes a la terminación del embarazo, independientemente de la duración y el sitio del embarazo, debida a cualquier causa relacionada con o agravada por el embarazo mismo o su atención, pero no por causas accidentales o incidentales (CIE-10).Se estima que cada año mueren en el mundo de 500000 a 550000 mujeres por causas obstétricas y que el $99 \%$ de estas muertes ocurren en países en vías de desarrollo (2,3). En el año de 1991, México fue clasificado como un país con alta mortalidad materna (4). A partir de ese año, se han hecho esfuerzos para reducir las tasas de defunciones maternas en la República Mexicana, sin observar aún cambios significativos (5).

En el año de 1993, se instaló en Yucatán el Comité Interinstitucional para el Estudio de la Mortalidad Materna, encargado de realizar un seguimiento de las defunciones y analizar las causas para disminuir el subregistro, pero se desconoce aún el porcentaje del mismo. Tomando esto en consideración, el conocimiento de la magnitud real del problema en Yucatán es cuestionable. Entonces nos preguntamos: 1.- ¿cuántas mujeres fallecen anualmente en Yucatán por causas maternas?; y 2.- ¿cuáles son los factores que no han permitido la reducción de las muertes maternas en Yucatán?.

Una metodología recomendada para el análisis de la mortalidad materna es su estudio por regiones.

Solicitud de sobretiros: Elsa Rodríguez-Angulo, Centro de Investigaciones Regionales “Dr. Hideyo Noguchi”, calle 59 x Av. Itzáes Núm. 490 Col. Centro, C.P. 97000, Mérida, Yucatán, México.

Correo electrónico: rangulo@tunku.uady.mx

Recibido el 2/Junio/2003. Aceptado para publicación el 3/Junio/2003.

Este artículo está disponible en http://www.uady.mx/sitios/biomedic/revbiomed/pdf/rb0314310.pdf

Vol.14/No.3/Julio-Septiembre, 2003 


\section{E Rodríguez-Angulo, F Uicab-Alonzo, J Ortega-Canto.}

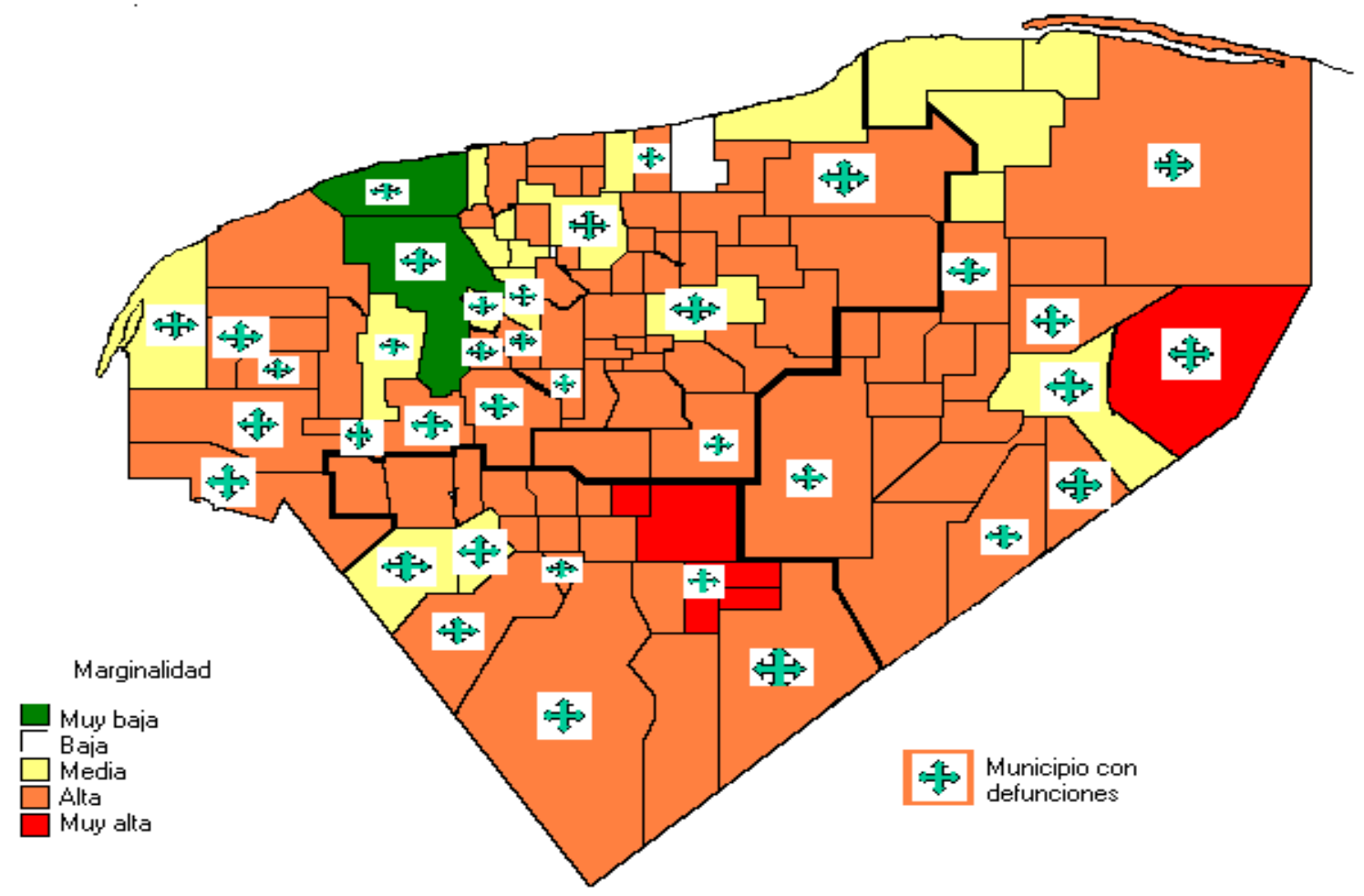

La regionalización permite identificar problemas específicos y tomar decisiones también específicas para esos problemas, así como enfocar programas adecuados para cada región (6). De 1997 a 2002, se registraron 124 defunciones maternas en Yucatán (Secretaría de Salud) y el $72.5 \%$ fueron mujeres que provinieron de regiones con altos niveles de marginalidad (CONEPO 2000) (figura 1). En el año 2001, el $87.5 \%$ de las muertes maternas ocurrió en el servicio de atención obstétrica de un hospital o clínica del Estado. Con estos resultados preliminares, sugerimos capacitar al personal en el llenado correcto de los certificados de defunción, para poder identificar las muertes maternas. Asimismo, es de suma importancia diseñar estudios para conocer los factores culturales, del Sistema de Salud y de los diferentes sectores de la sociedad, que ocupan un papel protagónico en el proceso de la salud-enfermedadmuerte materna. Esto permitirá generar nuevas hipótesis y realizar intervenciones adecuadas para cada región, y así incidir en los factores que sean factibles modificar, con un enfoque hacia la prevención de muertes maternas en Yucatán.
Palabras clave: mortalidad materna, Yucatán México.

\section{REFERENCIAS.}

1.-Elú MC. México: maternal deaths, fertility patterns, and social cost - an anthropological study. World Health Stat Q 1995; 48:49-7.

2.-Maine D, Wardlaw TM, Ward VM, McCarthy J, Birnbaum A, Akalin MZ, et al. Guidelines for monitoring the availability and use of obstetrics services. New York: UNICEF; 1997. p. 6-11, 15-16.

3.- Royston E, Armstrong S. Preventing maternal deaths. Geneva: World Heatlh Organization; 1989. p. 11-29.

4.- OPS/OMS. Plan de acción regional para la reducción de la mortalidad maternal en las Américas. Bol Of Sanit Panam 1991; 110:448-54.

5.- Comisión Nacional de Acción en Favor de la Infancia. México. Programa Nacional de Acción en Favor de la Infancia, 1995-2000. Evaluación 1996. SEP, México, 1997:147.

6.- Reyes-Frausto S, Lezana-Fernández MA, García-Peña MC, Bobadilla-Fernández JL. Maternal mortality regionalization and trend in México (1937-1995). Arch Med Res 1998; 29: 165-72.

\section{Revista Biomédica}

